\title{
Teaching Lighting Design for Cultural Heritage in the Digital and Pandemic Era: Experiencing New and Old Techniques
}

\author{
Andrea Siniscalco ${ }^{1, *(D)}$, Laura Bellia ${ }^{2}$ (D) and Lisa Marchesi ${ }^{3}$ \\ 1 Department of Design, Politecnico di Milano, 20158 Milan, Italy \\ 2 Department of Industrial Engineering, Università degli Studi di Napoli, Federico II, 80138 Naples, Italy; \\ laura.bellia@unina.it \\ 3 Mldlab Lighting Design, 20131 Milan, Italy; marchesi@mldlab.com \\ * Correspondence: andrea.siniscalco@polimi.it; Tel.: +39-349-6375450
}

Citation: Siniscalco, A.; Bellia, L.;

Marchesi, L. Teaching Lighting

Design for Cultural Heritage in the

Digital and Pandemic Era:

Experiencing New and Old

Techniques. Heritage 2021, 4 ,

3731-3748. https://doi.org/

10.3390/heritage4040205

Academic Editor: Francesca Pozzi

Received: 30 August 2021

Accepted: 16 October 2021

Published: 20 October 2021

Publisher's Note: MDPI stays neutral with regard to jurisdictional claims in published maps and institutional affiliations.

Copyright: (C) 2021 by the authors. Licensee MDPI, Basel, Switzerland. This article is an open access article distributed under the terms and conditions of the Creative Commons Attribution (CC BY) license (https:/ / creativecommons.org/licenses/by/ $4.0 /)$.

\begin{abstract}
In the context of the global COVID-19 pandemic, the world of cultural heritage has had to cope with the closures of museums and dedicated structures. In this dramatic context, the digitisation of assets represented a partial solution to guarantee the fruition of the world's cultural heritage. Even in the context of teaching, the pandemic represented a challenging moment. This contribution presents three different university teaching experiences focused on lighting for cultural heritage. The workshops described were held before, on horseback, and amid the pandemic. The differences are contextualised in the Italian regulatory and methodological framework. Attention is also paid to the digitisation of assets regarding the lighting design verification of the students' project proposals. The teaching approach, the procedures, the material presented by the students, and the revision methodology are described. The comparison between the three editions allows for evaluations of the main problems encountered in the different contexts and when the used procedures were instead strong points. The use of three-dimensional simulation, initially designed exclusively for lighting verification, has also proved crucial in the communication of students' works, demonstrating once more that in the future, the information technologies will be able to help those who deal with cultural assets to expand the catchment area and to enhance the communication of sites and museum structures.
\end{abstract}

Keywords: cultural heritage; digitisation; lighting design; teaching; distance learning

\section{Introduction}

The valorisation of the cultural heritage is a fundamental aspect of the conservation of the assets. However, unfortunately, some assets are not very usable by potential visitors even if of significant historical importance. This issue can depend on various factors, such as their conservation conditions (which can make them difficult to read), the unfavourable geographical position, restoration works with adverse effects on usability [1], the lack of resources to guarantee visibility, and numerous other factors [2]. Moreover, the abandonment of these sites often results in a situation where the maintenance and accessibility of the property become unsustainable from an economic point of view. For a long time, therefore, one of the aspects taken into consideration by experts is to make sites of cultural interest more attractive to potential visitors [3].

In the last twenty years, the improvement of acquisition technologies and their growing diffusion [4] have favoured the use of typical Information Technology (IT) methodologies to assist the dissemination of cultural heritage. Acquisition methods such as modelling, photogrammetry [5], or laser scanning have contributed to digitising a large part of the cultural heritage. The digitisation of assets can have the purpose of strengthening the communication of a site [6], favouring research on existing material [7] or promoting the classification of assets through multi-platform collaborative systems such as Building Information Modelling (BIM) [8]. 
The digitisation of cultural heritage has returned to the fore in recent times due to the COVID-19 pandemic, which, starting from March 2020, has resulted in the almost total closure of all museums and archaeological structures in the world. Therefore, the desire to recover from this dramatic situation immediately seemed urgent, as can also be seen from initiatives such as the manifesto "Cultural Heritage: a powerful catalyst for the future of Europe", published on 9 May 2020 by the European Heritage Alliance [9], in which ample space is dedicated to the relaunch, also thanks to IT.

During the pandemic, museums around the world reorganised themselves to ensure virtual accessibility as complete as possible. There are many options for the digital enjoyment of cultural heritage, including $2 \mathrm{D}, 3 \mathrm{D}, 360^{\circ}$ panoramic visualisation, photogrammetry, 3D reconstruction, 3D modelling, laser scan, Virtual Research Environment (VRE), or BIM technologies and Augmented Reality (AR)/Virtual reality (VR) applications [10]. Nowadays, the potential for interactions of visitors with the structures also in digital form is manifold; there are also collaborative platforms where one can upload their acquisitions of cultural heritage, such as the 3D Virtual Museum container site [11].

However, numerous museums of worldwide relevance [12-16] opted for a virtual museum consisting of $360^{\circ}$ panoramas integrated with information conveyed through different media (text, audio, video), many of them thanks to the support of cultural platforms such as the popular Google Arts \& Culture [17] which has established itself as the leading platform for virtual contents in museums [18].

In a context where technology, therefore, leaves maximum freedom, the real problem to be solved seems to be the choice of the most compelling narrative paradigm $[19,20]$.

\section{Lighting Design for Cultural Heritage: The Uni 11630 Standard}

Lighting design is one of the critical factors for the fruition of spaces, and cultural heritage is no exception. Indeed, the importance of light is even more significant as it helps to enhance the perception of shapes of three-dimensional works and can also have a decisive impact on two-dimensional ones [21]. In every part of the world, light exerts its strong influence on the perception of spaces, and it is a phenomenon so common that it is often almost taken for granted.

Cultural heritage is undoubtedly one of the main sectors in which the light culture requires more significant commitment [22]. Light is an essential component for the enjoyment of works of art: without it, we could neither see nor appreciate them, and our life would be decidedly impoverished. On the other hand, however, light with its radiations, whether of natural or artificial origin, is also one of the leading causes of the degradation process to which all cultural heritage is, to varying degrees, inexorably subjected $[23,24]$. Therefore, the utmost commitment must be made to allow the full enjoyment of the work, ensuring the best protection from damage of any origin [25-27]. At the same time, however, we must consider cultural heritage as places we do not live in but where we can observe, contemplate, and undergo very particular experiences. It is with this premise that we must approach the lighting project.

Cultural heritage is where a disciplinary confrontation between architecture, archaeology, history, graphics, geography, economics, and technology is necessary [28]; this is not so much for their knowledge but mainly for their conservation, enhancement, and use. All these considerations are fundamental when starting to design a lighting system for these environments. Artificial light is an essential element that allows one to integrate and qualify the perception offered by natural light [29], both when the latter is non-existent or too scarce or does not allow good modelling (perception of the three-dimensional shapes) or enhancement of the object [30]. Therefore, the lighting project for cultural heritage should consider fundamental aspects of history, culture, and sociology. It should also be based on all the technical aspects related to conservation and perception and be continuously updated by introducing new technologies, such as IoT (Internet of Things) systems, Bluetooth Beacons, and other solutions for the use of highly innovative integrative functions and applications. 
In order to guarantee a high-quality level of the lighting project for cultural heritage and standardise the documents necessary for its presentation, a standard has been established in Italy that defines the criteria for drafting the lighting project, specifying the elaboration process and the required documentation. This standard has been published by UNI (Ente Italiano di Normazione) with the name 11630:2016-Light and lighting-Criteria for drafting the lighting project [31].

This standard defines the process of analysis and processing of the lighting project in detail, both in the private and public sectors, specifying the documentation that must be developed at all levels of design. The UNI joins the Implementation Regulation (DPR 207) logic used for public works, offering a clear and straightforward methodological process dedicated to the lighting project.

Within the standard, it is possible to distinguish different application areas:

- Indoor environments: hospitals, hotels, offices, commercial, industrial etc.;

- Outdoor environments: parks, gardens, car parks, etc.;

- Indoor and outdoor sports facilities;

- Road systems;

- Architectural and monumental installations, internal and external;

- Tunnels and underpasses.

The standard applies both to constructing new lighting systems and the adaptation and transformation of existing ones. In addition, the document is integrated with informative appendices that detail what is specified in the specific application areas:

- Part A for indoor systems;

- Part B for sports facilities;

- Part C for road systems (motorised, cycle or pedestrian), outdoor areas, such as parks, gardens, car parks, etc.;

- Part D is for architectural and monumental systems.

Lighting design is therefore defined as a compendium of art and science capable of illuminating the human environment and includes photometric, ergonomic, and energy aspects and structured in these phases (Figure 1):

1. Feasibility study: provides the information necessary for decisions on the project relating to technical and organisational feasibility, benefits/risks, costs, and deadlines, to give substance to the design hypothesis;

2. Preliminary project: defines the qualitative and functional characteristics of the activities, the framework of the requirements to be met, and the specific services to be provided;

3. Definitive project: contains all the elements necessary for the qualifications, the assessment of urban planning compliance or other equivalent deeds (mandatory only for works in the public sector);

4. Executive project: defines the intervention to be carried out in full and in every detail.

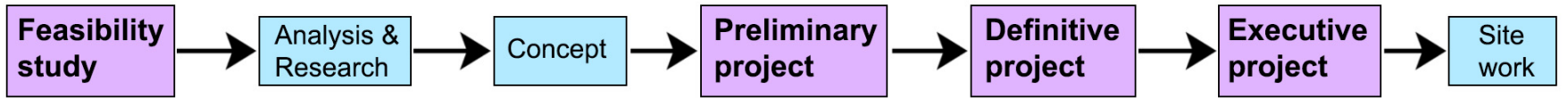

Figure 1. Simplified schematic of the lighting project as described by the UNI 11630: 2016 standard.

Another noteworthy technical specification is the European CEN/TS 17165:2018 [32], which defines the design and operation phases of the lighting system in the logic of sustainability and the circular economy. This standard also specifies the responsibilities of the lighting designer. 
The lighting project is structured in various phases, identified in the feasibility study, concept, preliminary project, final project, and executive project. For each stage, every element that constitutes the project must be made available in digital format by the designer in the forms described by the laws in force.

Each phase must be presented to the superintendent for approval, through a series of documents that can be summarised in reports (general, illustrative and technical), graphic drawings of the project (plans with legends, sections, prospectuses, details, collection of technical sheets), lighting calculations, environmental impact study, economic estimate or metric calculation, maintenance plan, and schedule.

Before elaborating the design concept, it is necessary to interface with the superintendency to work directly with the various actors (architects, engineers, historians, restorers, conservators, curators, etc.) to collect the multiple points of view and develop a project that can meet all needs.

Throughout the project's development, and for each step, it is always necessary to present the project and obtain approval to proceed. It is essential to carry out an on-site test to see the final effect proposed on paper when possible. The relationship with the team of superintendent professionals is fundamental to obtain a project that can emphasise the multidisciplinary aspects of the cultural heritage.

\section{Lighting Design Software}

As part of the lighting project, it is customary for the designer to use various digital tools that can assist him in producing the results.

However, there is no accurate indication of which software packages are best suited to design. Additionally, the already mentioned UNI:11630 does not detail specific tools to be used. As regards the graphical drawings, it remains very open to the type of data representation. Terms such as "photo simulations" or "graphic rendering in an appropriate scale" are used without specifying the production method of these elements. Consequently, each designer is free to adopt the techniques he deems appropriate to simulate the project's appearance, from the production of photo simulations with raster imaging software to the use of 3D applications for the production of photorealistic renderings.

In lighting design, however, photorealistic images are not everything that is needed. An image can be beautiful and appear realistic to the final user, but this does not mean that it also simulates correctly the appearance of the space illuminated with the selected fixtures. Many of the architectural renders that can be found are images whose primary purpose is to "sell" the project to a client and not necessarily be photometrically accurate.

In the UNI:11630, emphasis is instead placed on the possibility of using lighting calculation software as long as they are "validated". This means that the software must comply with the criteria set out in the technical document 171:2006, produced by the technical committee 3.33 of the Commission Internationale de l'Éclairage [33]. The most popular lighting design software are Agi32 [34], Dialux [35], Relux [36], Litestar [37].

Generally, lighting calculation software are not particularly complex in terms of modelling, texturing, and material management tools. This makes the time required to master them considerably less than that of representation software but causes apparent limitations in generating photorealistic images. The lack of photorealism in verification software is that when designers want to obtain high-quality images (for large commissions or big tenders, for example), they find themselves having to resort to other tools. These might be the $3 \mathrm{D}$ modelling programs themselves or other solutions, such as photo manipulation with raster editing programs.

In the future, this issue will probably be normalised with the spread of the Building Information Modelling (BiM) approach [38]. Still, as it is, for now, the use of 3D lighting verification software is the most diffused method. 


\section{Investigations, Surveys, and Asset Protection: The CEN/TS 16163-2014 Standard}

Before even starting with lighting concepts in the field of Cultural Heritage, it must be observed that each object of intervention represents a unique case, owing to the enormous variety of typologies in terms of dimensions, historical period, materials, the actual state of conservation, and proposed new functions [39]. Indeed, the objects of intervention can involve both outdoor places, such as historical centres, monuments, squares, archeologic sites, and indoor spaces, such as historic buildings with different functions, or museums [40]. Regardless of whether indoor or outdoor, all the lighting proposals should comply with the two following and sometimes contrasting instances: allow visitors to enjoy cultural heritage material and at the same time preserve it from damage, in order to bequeath it to future generations. Light plays a relevant role in establishing a direct and emotional connection between heritage objects and observers [26,41], but can produce damage on sensitive surfaces and, combined with other environmental parameters as temperature, humidity, and pollutants, can be responsible for phenomena such as fading, cracking, growth of mildew, and bacteria [42]. Moreover, in most cases, lighting fixtures and installations must be reversible without determining permanent modification to the structures. Buildings of high historical value or collections contained in them are often subject to constraints, and the design proposals must accomplish all requirements posed by Superintendence. On the other side, lighting must be carefully designed for enhancing visual perception in harmony with the characteristics of the environment, avoiding discomfort, and limiting energy consumption. For these reasons, accurate preliminary surveys are necessary to address the design strategies toward the most effective solutions. Furthermore, an analysis of optical characteristics of surfaces in terms of spectral reflectance can help choose the most appropriate light sources' spectral power distributions (SPDs), especially in the presence of different surface colours [43]. Today, LED technology allows the build of SPDs specifically designed according to the chromatic characteristics of objects and surfaces [27,43-45].

In the presence of sensitive materials, lighting must be carefully designed and dosed to limit photochemical reactions, radiant heating effects, and growth on biological organisms [42]. The absorption of photons induces photochemical phenomena that manifest as changes of colours or mechanical properties [44,45]. Unfortunately, these changes are irreversible and depend both on the wavelength and the incident radiation amount. Generally, the most dangerous wavelengths are the short wavelengths, so it is necessary to avoid exposure to UV radiation $[46,47]$. This can be easily achieved by employing LED sources, which usually do not contain any UV radiation, or by adopting specific filters. IR radiation should be avoided as well, being unnecessary for vision, because it can induce heating effects that can damage surfaces. Even visible light can be dangerous, so the standard CEN/TS 16163:2014 [48] reports illuminance limits, expressed in lx, and annual exposure limits, defined in lx.h per year as a function of the material sensitivity. Indeed, all materials are classified, according to this standard, into four categories from "insensitive" to "high sensitivity", and for each type, different limits are adopted. It must be noticed that for high-sensitive materials, for example, organic materials, the maximum permissible illuminance is only $50 \mathrm{~lx}$, so lighting designers must find challenging solutions which allow the complete adaptation of the human visual system to these low illuminance values and at the same time achieve adequate visual performance and comfort $[49,50]$.

Things are much more complicated when, in indoor spaces, daylight is a part of the visual environment. In this case, given its variability both in intensity and spectrum, additional analyses must be performed to avoid over-heating, damaging, and glaring effects and, on the other side, to suitably integrate daylight and electric light [51]. This is not an easy task, so daylight is sometimes excluded for conservative purposes and to simplify the procedures. When possible, especially in environments where daylight provides additional value in terms of spatiality and connection with the exterior, the visual environment can be controlled through automatic systems based on illuminance sensors. In this way, it is possible to regulate daylight provision and modulate lighting fixtures' outputs according to the different conditions. Although today's technologies can change the light sources' 
SPDs over time, this is often a problematic and expensive feature to include in the design project. Still, it deserves to be considered, given the rapid technological developments.

Automatic controls, based on presence sensors, can also be adopted to reduce annual light exposure by switching off lights or reducing luminous fluxes in the absence of visitors. However, even in this case, design strategies must consider paths of visit and avoid undesirable fluctuations of light.

Damage can be produced by radiation and environmental conditions and by the electric system's components, given the frequent necessity to install cables and luminaires on precious and ancient structures. For this reason, lighting solutions must not be invasive, they must be reversible, and all the components, including luminaires, must be appropriately integrated into the environment and pleasant to see.

\section{The Lighting Design Master of Politecnico Di Milano: The Workshop on Cultural Heritage}

Numerous academic and non-academic realities provide lighting design courses, guaranteeing architects, designers, and engineers the skills necessary to tackle a lighting project in its entirety. For example, in Italy, the university Politecnico di Milano offers a specialising master program in lighting design with eighteen editions. The program consists of a first part dedicated to the fundamentals (lighting technology, CAD for lighting, LED technologies, smart control systems, daylight, culture, and design of light) followed by a series of workshops in which students join in groups to tackle real case studies in the main areas of lighting design, followed by professionals and academics. One of the workshops addressed as part of the program is lighting for cultural heritage.

The design workshop of the master is presented as an intensive course in which groups of students are asked to develop a lighting project for a cultural asset.

The course's main objective is to offer students the tools necessary to understand a design method that starts from analysing the "problem" and arrives at the definition of a possible solution proposal.

During the workshop, students are offered thematic presentations of case studies, a whole series of design tools, both theoretical and practical, which guide them through the project's development.

Practical examples of professional projects or studies are examined with the students. Then, the most commonly used light sources are presented in their technical aspects; Correlated Colour Temperature (CCT), Colour Rendering Index (CRI), Ultra-violet, and Infra-red radiation. The next step is the lecture on practical lighting effects; direct and indirect, diffused and accent, ambient lighting, etc., all applied to museum spaces, temporary exhibits, and architecture. The course goes on until the deepening of the topic of the luminaires, be they standard or custom, thus addressing the issue of product design.

By developing a case study project, students can then analyse the project from the point of view of the lighting effect and the product's design, thus addressing the two main aspects of lighting for cultural heritage.

Lighting for cultural heritage differs from other applications because no standardised typologies exist. Each case must be treated as unique, historical and architectural issues must be approached with technical competencies, and solutions should satisfy all the conservation and exhibition requirements. Cultural heritage covers many cases, from historical buildings of different ages and sizes, historical centres, museums, collections, and archaeological sites [52,53].

So, unlike other lighting applications, such as lighting for schools, hospitals, or even retail, little standardisation can be considered. Moreover, in many cases, the necessity to design a lighting system is strictly connected to a restoration intervention to give new life to the studied historical building, so the restorer architect's decisions can affect lighting designers' choices. Sometimes, the spaces have different purposes from those they originally had. For example, they may become spaces for exhibitions or even acquire new functionalities such as meeting rooms, conference rooms, libraries, etc. In these cases, two contrasting aims need to be harmonised: to create a luminous environment that recalls 
the history of the building, obtaining a pleasant appearance and atmosphere, and provide the proper lighting levels necessary to perform the assigned visual tasks. For this reason, technique and creativity are often both necessary to find suitable lighting solutions.

Sometimes new luminaires' features can be created; the most advanced lighting techniques can be applied for obtaining smart and sustainable solutions. When indoor spaces are used as museums or for exhibition purposes, the visit tour plays a significant role in lighting decisions; furthermore, the use of daylight must be accurately evaluated $[54,55]$ and, when possible, maintained and managed through proper control systems [56,57]. Those mentioned above are only some of the countless cases that can be a case study for a teaching program on cultural heritage. For these reasons, it firstly becomes necessary to make the attendants aware of the complexity of cases and give them a method to approach the analysis and subsequent design phases. Students learn how to balance with lighting the contrasting conservation needs, enhance and utilise by analysing the case study, discuss problems and proposals among themselves and tutors, and experiment with possible solutions. It must be noted that students come from several countries worldwide, and their approach to cultural heritage issues is sometimes completely different. If in Europe, and specifically in Italy, all interventions are mainly conservative; in other countries, for example, in South America or Asia, other instances are considered [58]. In addition, students have different educational backgrounds: designers, architects, electrical engineers, and mechanical engineers. Some of them have only recently graduated; some others have professional experience. These differences among students represent a point of strength: it is from the diversity that all issues are tackled from several points of view to explore and compare new proposals with an open-minded approach led by tutors. Students perform their activities and develop their design ideas in groups of three or four people (only seldom are groups composed of two people). When possible, groups should be heterogeneous to stimulate comparisons of ideas and develop the ability to work with people with other cultural and geographical backgrounds.

Students are assigned a case study, generally sufficiently complex but relatively small, to be addressed and completed during the workshop. The case study is the same for all groups, with minor differences.

The final output of the workshop is to develop a lighting design in its final form but not in its executive form. The proposed plan must comply with the standard UNI 11630. Starting from the historical analysis of the site must show results obtained from all the methodological steps learned during the workshop. It is possible to make use of all the available tools that the students consider helpful in describing their proposals: sketches, lighting software results, rendering tools, mock-ups, prototypes, etc., as they are judged to be more effective.

The same case study for all groups allows one to obtain a variety of solutions that can be compared, enhancing pros and cons for all of them and confirming how light plays a significant role in the cultural heritage field and how much it requires competence and experience.

In synthesis, it can be affirmed that this workshop represents for attendants one of the trickiest tasks among other workshops in lighting, but at the same time one of the most fascinating.

\section{Teaching at the Time of the Pandemic: Three Editions of the Workshop}

Even though the master has been running since 2004, the last three editions of the cultural heritage module have been unique. They are therefore an interesting starting point to address the topic of teaching.

The first of these three editions, made before the pandemic, was structured with the classic layout of classroom lessons. The didactic path has been similar to all previous editions, i.e., forty hours total, frontal lectures in the first phase, and revisions of the material produced by the students in the second phase. 
From the point of view of the organisation of the lessons, there were no significant differences between the three editions. Still, the first, which saw the students in the presence, allowed a more fluid interaction.

The frontal lessons are carried out in the classroom by projecting images and brainstorming to confront all the students. In this phase, it is advantageous to explain some aspects of light and bring lighting products to students for a hands-on demonstration.

When students are present, it is possible to operate samples of light sources to be able, for example, to point out the difference in colour temperature, to understand how the light reacts with different materials (opaque or glossy), and in the design phase to be able to review mock-ups integrated with light created by the students to explain their design concept better.

It is possible to leave the students to work freely in a group and to be able to follow them during the development of the project, making ad hoc reviews for each group, building the project directly together, and defining step by step the most appropriate deliverables to improve the quality of their work.

In the first edition, the case study was the lighting for the Albergo Diurno Venezia in Milan [59]. It was possible to organise an on-site visit with the architect of the association Fondo Ambiente Italiano [60], responsible for the restoration, who presented the asset to the students (Figure 2).

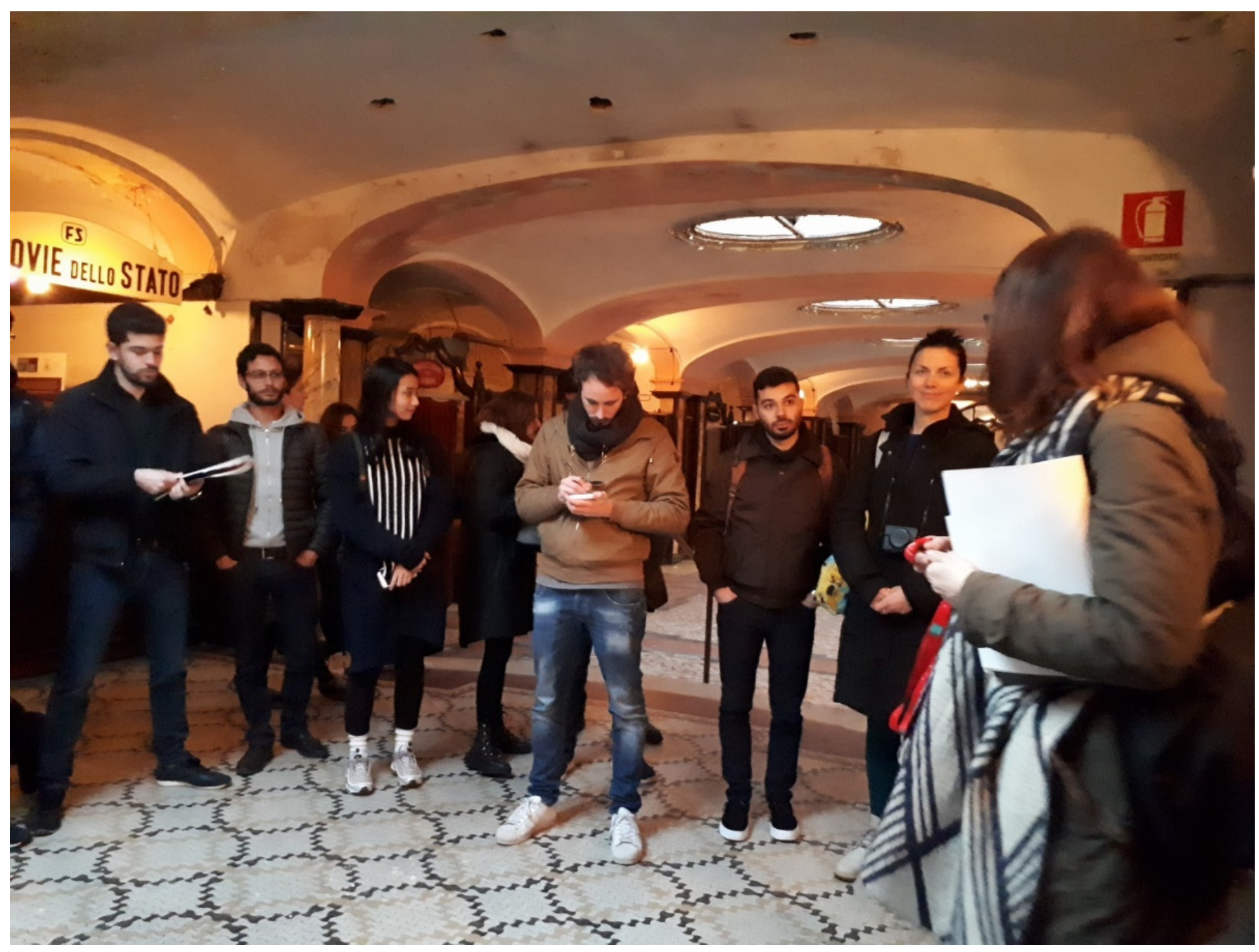

Figure 2. Students of the master on a site inspection at the Albergo diurno Venezia. 
The possibility of carrying out an inspection was essential for the students to understand the architectural difficulties of the space and help them know how to deal with the lighting project. This fundamental aspect cannot be addressed with distance lessons only, if not by organising virtual visits.

The empathy created with the students also allows creating a specific path for each group, finalising the reviews concerning each student's abilities, interests, and predisposition towards some issues rather than others.

The second edition, on the other hand, happened to be hybrid. The lectures had begun before the pandemic broke out in Italy. As a result, the introduction lessons, the first development of research analysis, and the concept presentation were done in person. In contrast, the second part, where the students started defining the project, was done remotely.

In this second experience, the case study was the Abbey of S.Maria in Cerrate in the province of Lecce [61].

The course also suffered the reorganisation of the schedule of the entire program. The direction of the master had to readapt the calendar to make it possible for every student to attend the lectures. The difficulty was that students were spread in many time zones, so it was challenging to build a suitable schedule.

Because of this reason, students started with the workshop on cultural heritage, interrupted it due to lockdown, and resumed it at the end of the entire program, right after all the other modules. This allowed the students to tackle the heritage module, which has always been the most complex issue, with more significant experience and awareness.

The hybrid approach complicated the management of the module, and it was also the first time the courses were held on a digital platform.

The most complex aspect of the module's distance learning was the revisions carried by VoIP software, namely Skype [62]. The reviews were done one group at a time instead of in front of the whole class, as before. The schedule of these revisions had to be set following the time zones of the various students; this was difficult to manage and did not allow the sharing of the reviews. The absence of the sharing discussion with all the groups made it impossible for the students to compare ideas and improve, and the most direct consequence was that many works were similar to each other.

The third edition, the last of 2021, was born as distance learning and was immediately organised with the Cisco Webex platform [63], which has always made it possible to create a class lesson (Figure 3).

Always using alternation between lectures and reviews, it was possible to carry out group reviews with the permanent presence of all students with this platform. The case study of this edition was the same as the previous one. From a teaching point of view, the use of lighting verification software was beneficial. Students used the Dialux Evo software taught at the beginning of their didactic program and it is probably the most diffused solution in Europe. It is free and has numerous tools to help the lighting designers see if their project meets the desired results. This software makes it possible to plan, calculate, and visualise lighting for indoor and outdoor areas. It is possible to see an entire building or individual rooms and create different outputs: artificial and natural light showing various scenes and atmospheres. The results can be visualised as diagrams, non-photorealistic renders (false colours), and other ways that help realise if the project meets the requests (Figure 4).

During the revision with the students, it was possible to navigate the 3D model and work from remote analysing each area. Thanks to the use of this application, the students could explain the idea with render and calculation, so in the same revision, it was possible to check the effect of the light and all the necessary technical aspects. From a timing point of view, the positive side of online teaching is that students respect the project exposure times, which are very important on a professional side. This edition has had excellent results, despite the difficulty of the groups not physically working together. This has led to the development of only presentations without creating models or printed boards, which, 
on the other hand, are still very important on a professional level. At the same time, with the digitalisation of the didactic, another important aspect was the improvement of the final presentation that, in some cases assisted by the use of Dialux Evo (and more), helped the students to create 3D media that guided the teachers with a virtual visit inside of the cultural asset, showing the lighting effect.

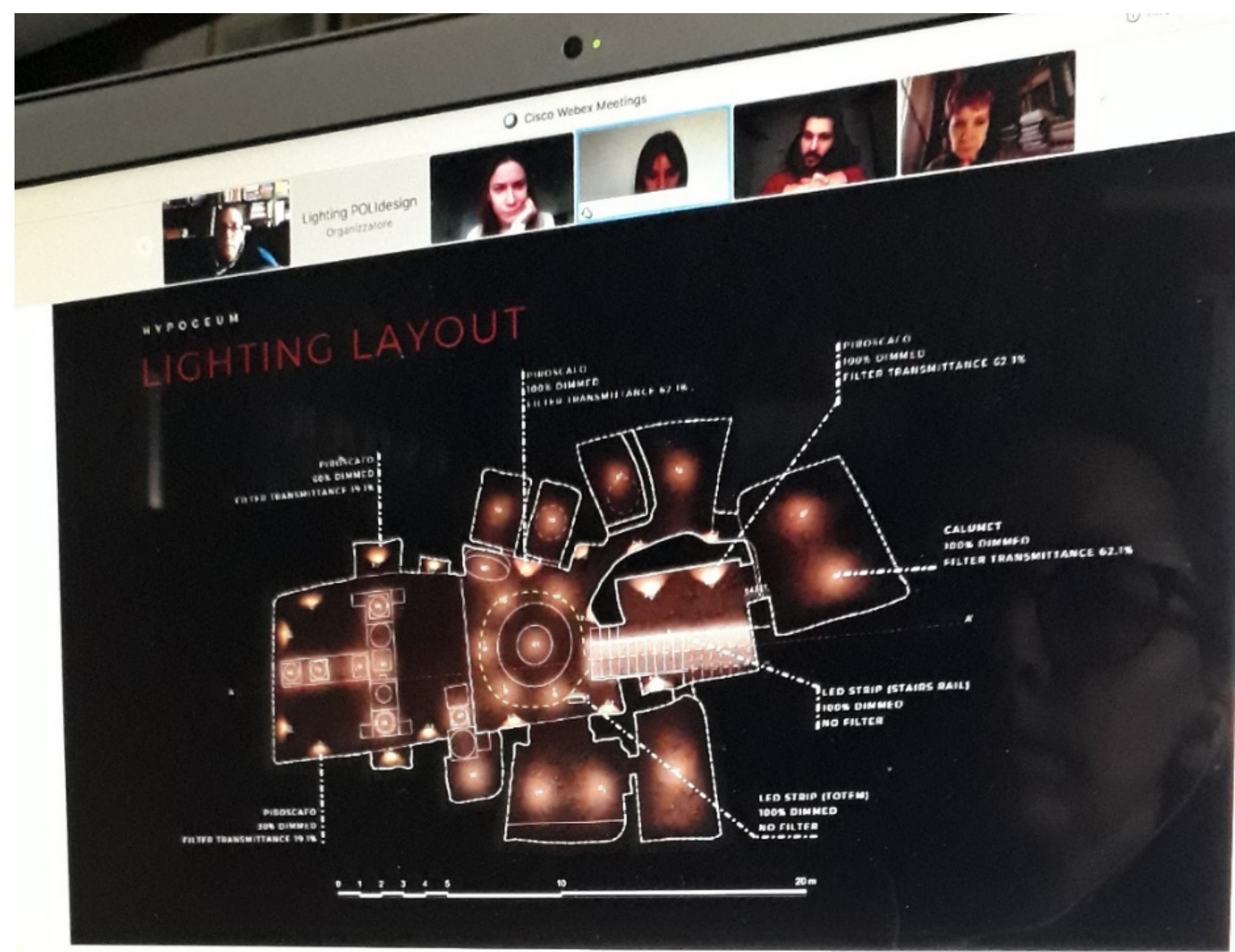

(8)

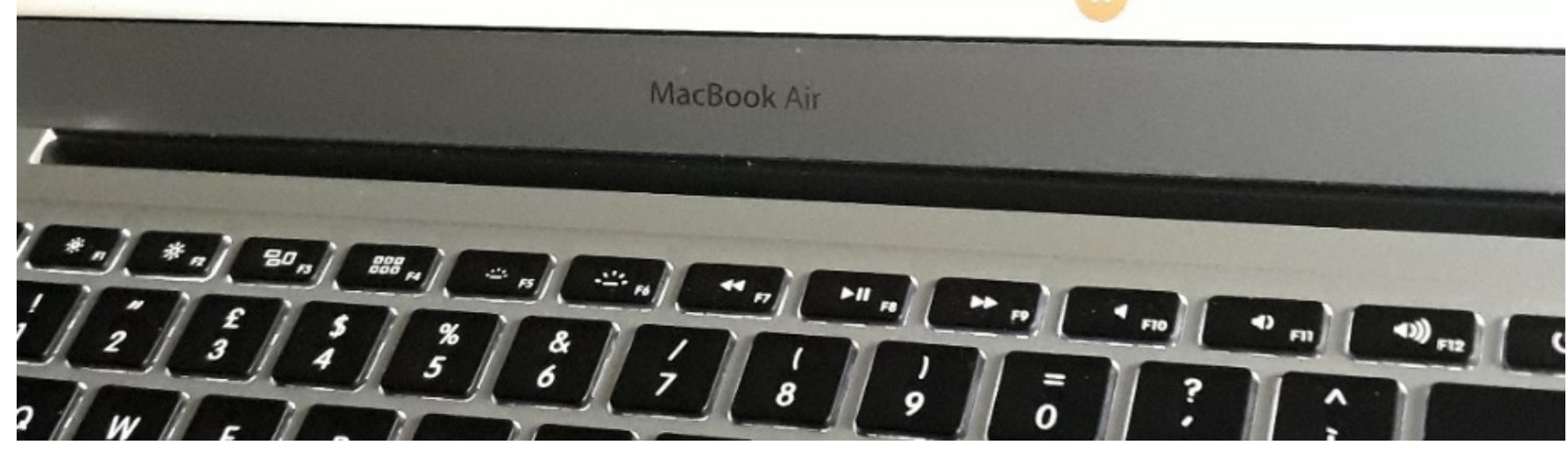

Figure 3. Students of the master present the concept of their work on a web-conference app. 


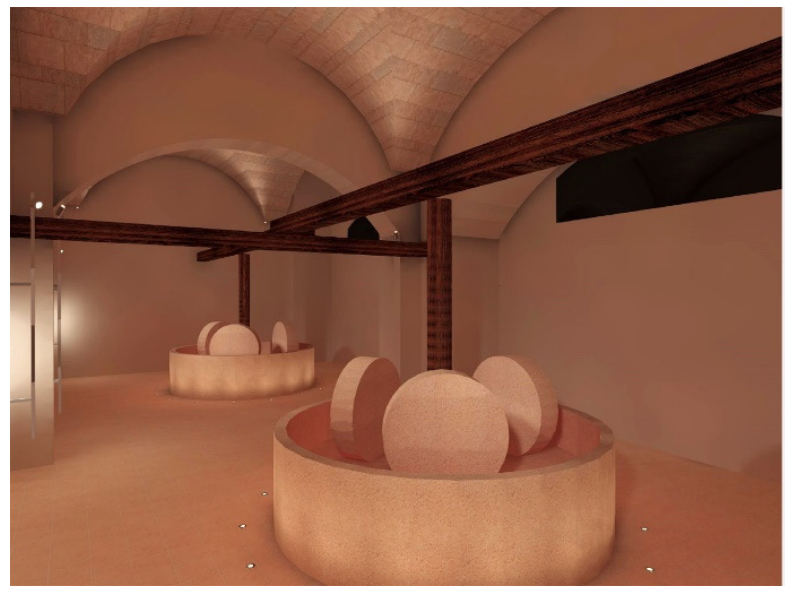

(a)

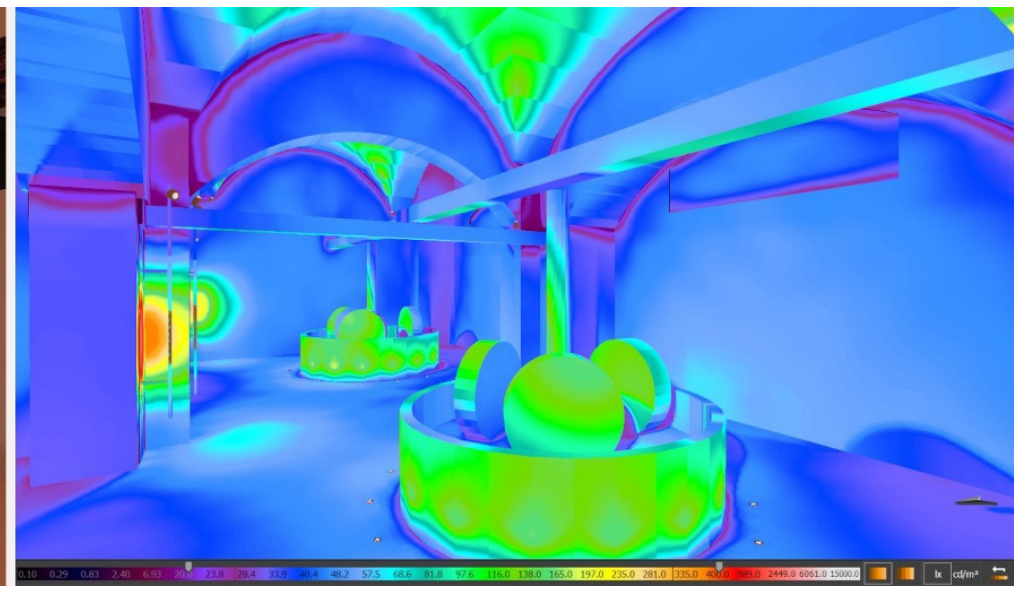

(b)

Figure 4. (a) Render of a room in the abbey of Cerrate. (b) Non-photorealistic render of the same room showing a false colour image of the illuminance of the lighting designed by the students. Students: Julio Angelo Sardalla and Shreya Rao Tekumalla.

The lighting projects were presented differently with this software, showing technical aspects, different scenarios, and even custom-made lighting fixtures.

\section{Reviews, Method, Deliverables}

From a teaching point of view, the module sees a series of frontal lectures at the beginning in which the main concepts related to the theme of lighting for cultural heritage are explained to students.

The second part of the course is dedicated to the development of the project by the students. Thus deepening lectures and revisions, in groups or with the whole class, are carried out in this phase. In addition, a series of intermediate class deadline reviews are organised to mark the course of the workshop, following the evolution of the projects. Both the request for documents and the revision steps follow the standard design process structure typical of Italy.

Presenting a lighting project for a cultural asset in Italy, where all interventions are often subject to the superintendency's approval, means aligning the designs to a standard model. Therefore, the documents requested during the various design phases (preliminary, final, executive) defined the students' deliverables.

The typical standard phases of the lighting project for a cultural asset were presented to the students. Still, only a part was required for the course, both for available time and competencies, and because many phases have only professional meaning and would not be helpful for the students.

Therefore, it was decided to focus on the first stages of project development instead of the execution stages. Because of that, the relevant design phases of the course were: Analysis and Research, Concept, and Preliminary Project.

The groups had to present the available research about lighting concept for cultural heritage: pictures of cultural heritage projects referred to different light functions: emotion, art, communication, functionality, entertainment, safety, interactivity etc.; analysis of technical and law aspects for cultural spaces and underground places; analysis of the specific site: pictures of the area with comments and sketches about positive and critical situations, lighting analysis (general lighting, accent lighting, atmosphere light, decorative light, communicative light), analysis of the natural light; summary of the complete research through reference images and a schematic diagram. 
The next phase sees the students present the lighting concept through sketches, diagrams, photo-rendering, mock-ups (with paper, cardboard etc.), and reference images to explain the lighting effects chosen for the concept (Figure 5).

On the last day, groups of students had to do a slides presentation with the A\&R+Concept and Lighting project summary. In addition, every group had to prepare technical drawings (UNI A3 format) with the general plan showing the position of luminaires and a list of the fixtures (number, technical specifications). Other tables were sections with elevation and placement of the lighting fixtures, details of installation of the products, and how the light was integrated into the architectural components, with mock-ups of some of the special proposals. Three-dimensional models with lighting analysis were also delivered together with videos, if necessary, to explain the concept (Figure 6).

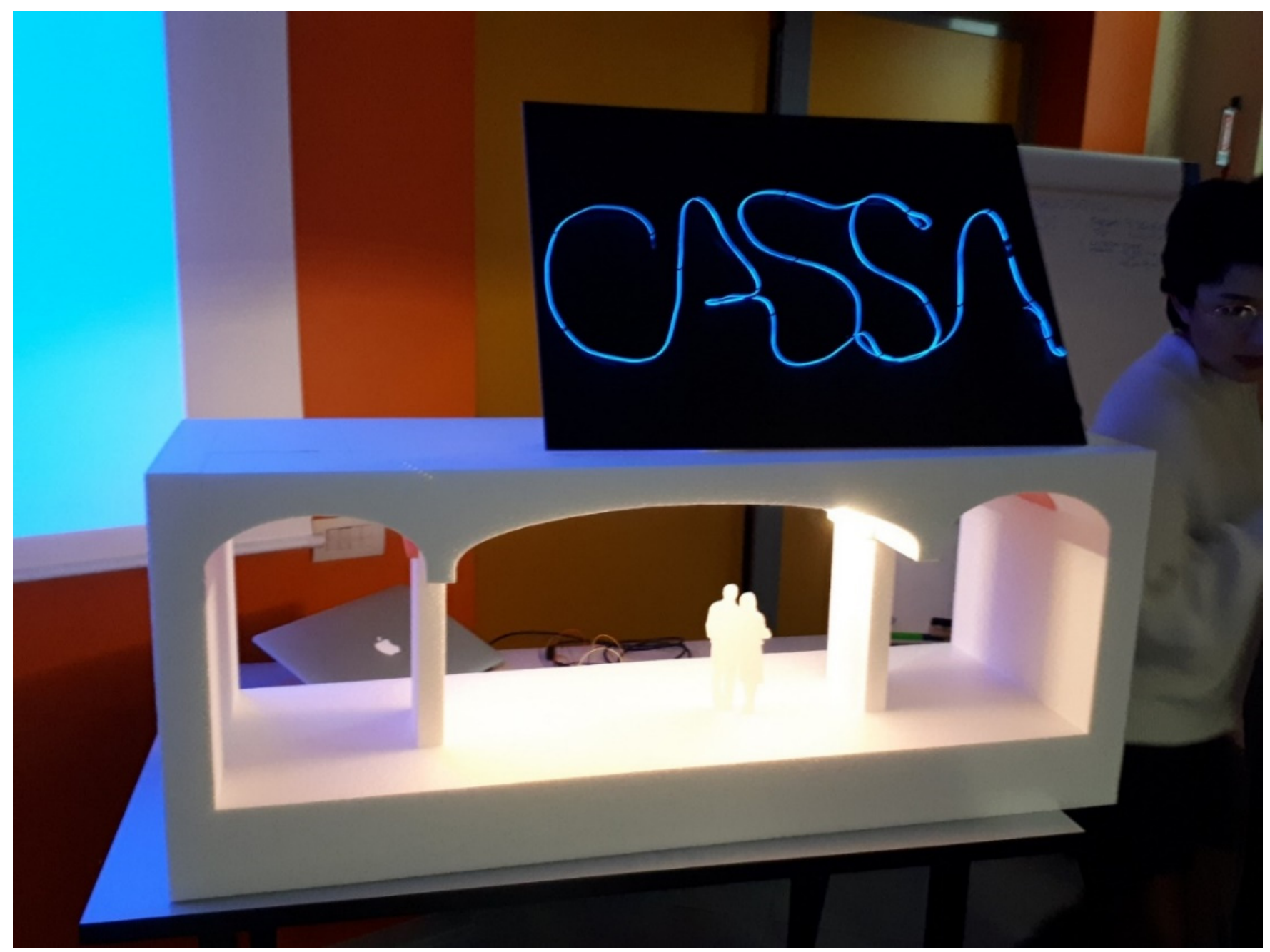

Figure 5. Students of the master presenting a mock-up of their project for the Albergo diurno Venezia. Students: Alagol Nil, Silvia Bertelli, and Ipek Ozmen. 


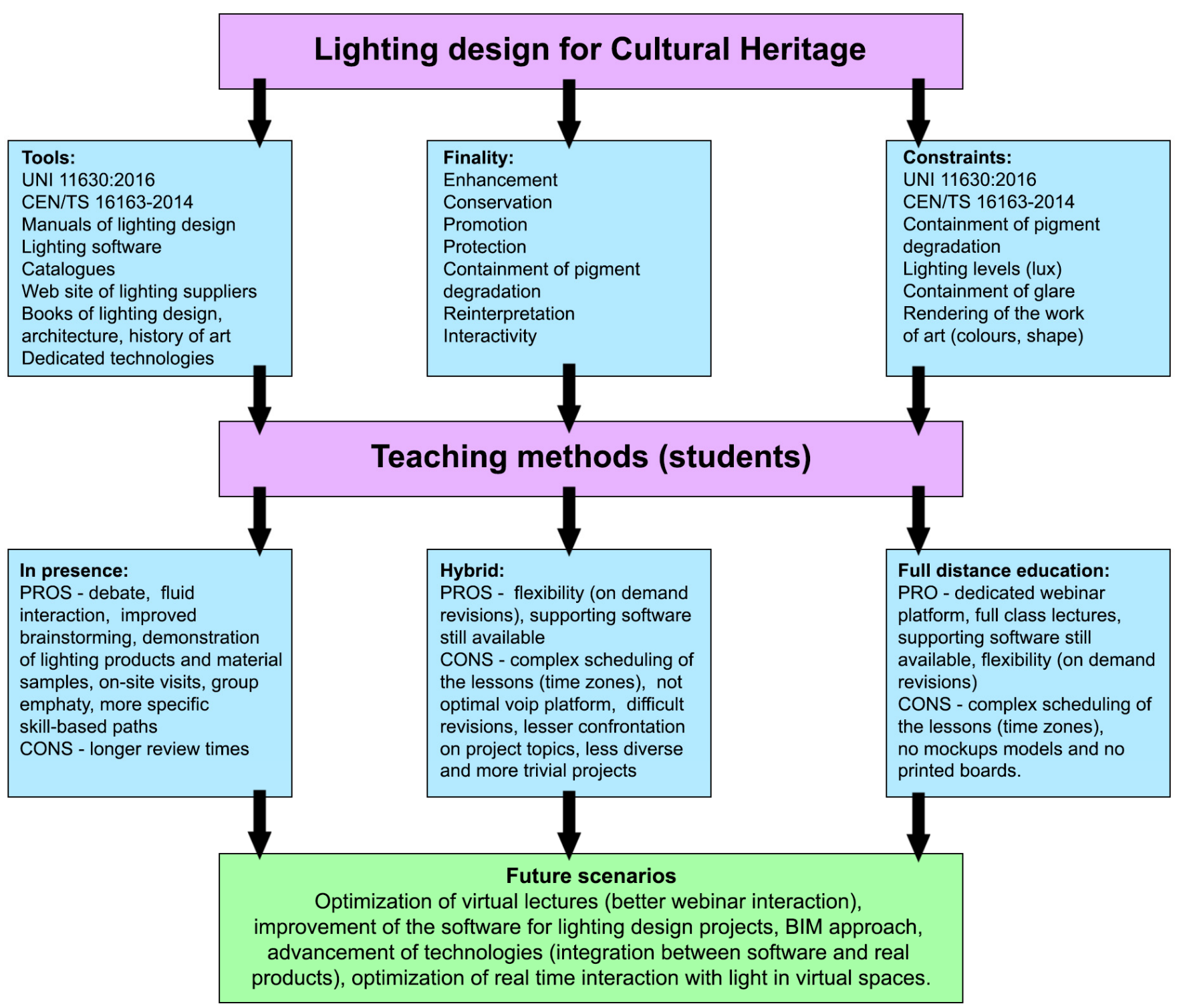

Figure 6. Scheme of a possible project of lighting design for cultural heritage applied to three different editions of a specializing master's workshop. These editions were different in approach to the class. The first was entirely in person, the second was hybrid (it was interrupted by the COVID-19 pandemic), and the last was entirely through distance learning. Possible future scenarios of lighting design for cultural heritage teaching are also put in evidence.

\section{Conclusions: What Have We Learned}

These three teaching experiences held before and during the COVID-19 pandemic allowed evaluating positive and negative aspects of different approaches in Lighting for Cultural Heritage workshops.

From an organisational point of view, the main issues were due to the different locations of the students around the world. In addition, the full distance learning edition had students that spanned eleven time zones; this resulted in the impossibility of having full class lectures exceeding four hours. This can be acceptable for frontal lessons, but it is not sustainable if the teachers want to revise the entire class collectively.

Concerning the management of the class with the help of webinar software, no significant problems were encountered. With the appropriate tools, one can process frontal lessons and even revisions remotely; it is possible to tackle a design workshop with excellent results. For the full distance learning edition, we used the Cisco Webex platform, but during 2020, for obvious reasons, a big step was taken in the industry of online education software. 
Many tools were improved, and many others with new functionality were born. Multiple solutions can be accessed to customise at maximum the teaching experience, from the creation of a webspace for the course (with tools like Moodle [64]) to quizzes and surveys with software like Socrative [65].

Creating more and more flexible digital tools for distance learning and work is a clear indicator that, even when the pandemic is over, the online option will still be an excellent way to improve classes and boost the participation of people to higher levels.

Concerning the dynamics of the students involved in the project, a positive note is that in the frame of a tightly planned schedule (due to distance learning), students appear to be more inclined to respect the deadlines for revisions and final exams. This is a fundamental aspect for everyone to be prepared for the professional world.

The most negative aspects of distance learning (also when there's the possibility of a hybrid approach) seem to be connected to the lack of interaction. Students have more difficulties in generating empathy toward each other. Additionally, during the discussion of their work, they appear to be focusing only on their part of the speech, refraining from intervening when questions or comments are made about the parts presented by group mates. This behaviour does not encourage a holistic approach to the project that ends up in just a sum of parts created by different persons.

Other than the lack of empathy, the impossibility of showing actual products and material to the students limits the inspiration that sometimes grants the spark that can grow into an innovative solution. Of course, it is possible to use webcams or datasheets to show the devices, but the quality of the video and the lack of detail and tactile feedback are definitely to be considered. The impossibility of visiting the site of the case study is also another turndown. A possible solution would be to use digital technology to compensate for this aspect. It is possible to digitise the space, integrate it with information, and make it navigated virtually. The 3D models could also be exported to be used with three-dimensional lighting verification tools. However, this aspect still needs a lot of work from the software house to optimise geometries for this purpose.

\section{Future Scenarios: Optimisation for the Virtual Approach}

In lighting design, it is common to verify the design hypotheses in lighting calculation software. These software packages have numerous advantages (integrated product catalogues, the possibility of creating comprehensive project reports, etc.) and various limitations, especially regarding interactivity and the reuse of resources for other purposes (non-exportable models, difficulties in communicating with other software, proprietary files, etc.). However, the efforts made in the design and verification phase (Figure 7) could easily be exploited by reusing the digital material to extend the usability of the asset beyond regular use on site.

While requiring some effort due to the optimisation of the models, this process would guarantee the asset to be reached (in virtual form) even by many distant users or those that cannot attend for reasons such as the pandemic.

Models built for lighting verification can be navigable according to the X3D standard [66], now in its fourth incarnation. With the advancement of technologies [67], it is also possible to envisage integrating these 3D navigation standards with some promising interfaces such as Unity [68] or Unreal engine [69]. This last interface also offers the possibility of simulating lighting in an advanced way thanks to optimising geometries (also adapting them to less performing systems) and using algorithms to calculate global illumination in real-time [70]. This would allow the visitor of a hypothetical virtual museum to choose the natural lighting conditions such as the time of the visit, the atmospheric conditions, and even interact with the artificial lighting by choosing the parameters they prefer. 

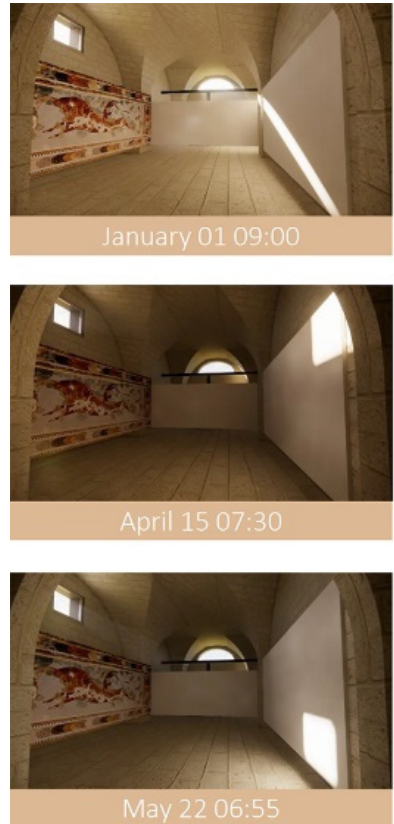
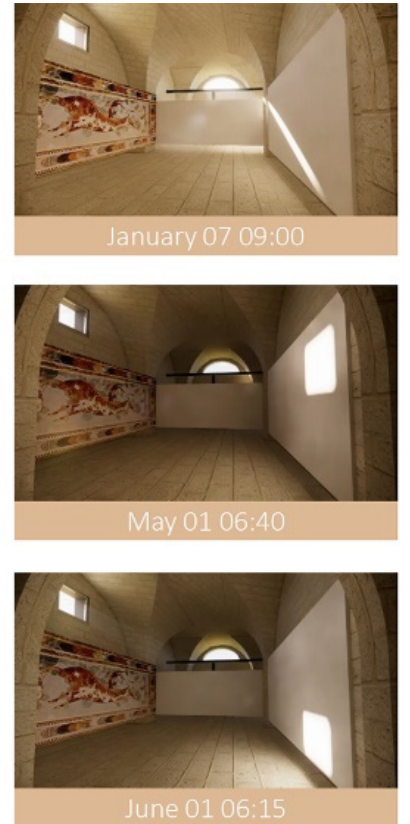
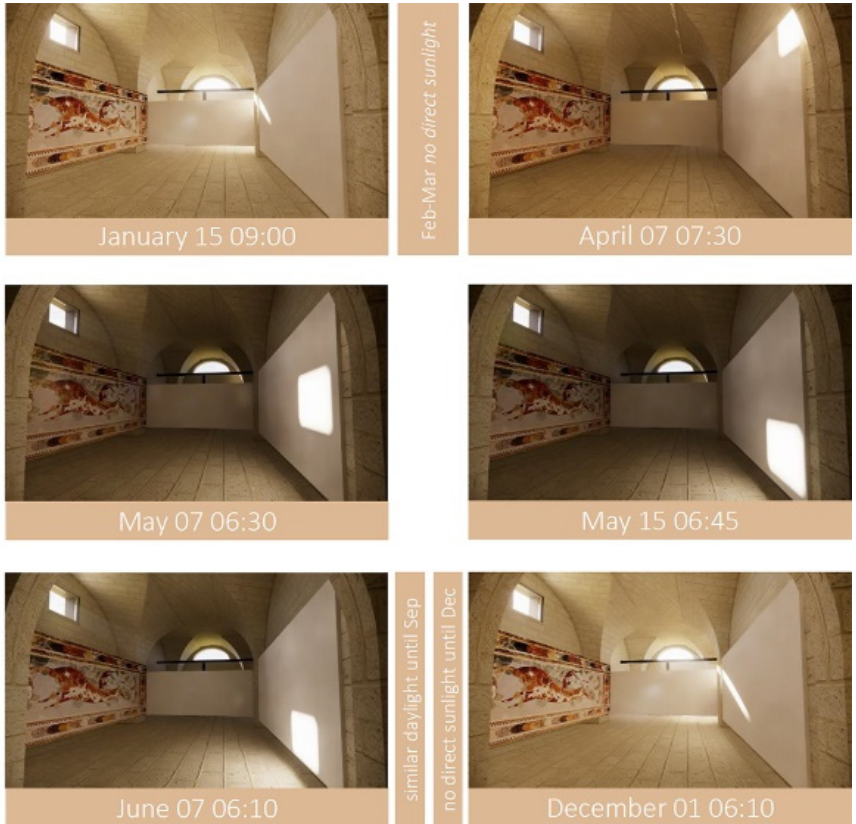

Figure 7. Daylighting analysis of the interiors of the Abbey of Cerrate done with the lighting simulation software Dialux Evo. Students: 17- Schnelle Ritika Gopalan, Mesrop Hayrapetyan, and Sunny Sharma.

The problem with these systems is that they were not developed for lighting design but rather for entertainment and architectural visualisation. Nowadays, numerous calculation engines can provide physically based results that are quite correct from a photometric point of view. However, since these systems have been designed for other purposes, they lack the tools and interfaces to make them suitable for verifying and visualising the lighting project.

The solution of this problem, and plausibly, the union of all the features that software capable of creating navigable and interactive environments (even with limited hardware resources), where the light-matter interaction is calculated photometrically and with actual lighting products, will probably be studied in the context of BIM approach. Developing software from scratch, with the awareness that soon the world of design (also that of structures to contain cultural heritage) will turn to BiM software, could be short-sighted. The hope is that in the years of development that await the world of software programming, the software houses will have the will and foresight to work holistically, trying to leave room for the creation of plugins that can assist designers in multiple sectors, not least that of cultural heritage.

Author Contributions: A.S., as deputy director, coordinated the program and tutored the master in which the workshop took place. In addition, he taught in the program covering the topics of CAD for lighting, providing students with the software tools to tackle the module on cultural heritage. L.M., as a teacher, introduced the topic to the students and then taught them the procedures and the design method for lighting projects in the field of cultural heritage. L.B., as a teacher, held lectures dealing with damage effects of lighting on sensitive materials, standards about the preservation of artworks in indoor environments, optimization between visual and conservation needs, and analysis of daylight variability. Both L.B. and L.M. held revisions with students and carried out a final exam session for the three editions discussed in the contribution. Conceptualisation, A.S., L.B. and L.M.; methodology, A.S., L.B. and L.M.; project administration, A.S.; visualisation, L.B. and L.M.; writing-review and editing, A.S., L.B. and L.M.; writing-original draft, A.S., L.B. and L.M.; and supervision, A.S. All authors have read and agreed to the published version of the manuscript.

Funding: This research received no external funding.

Institutional Review Board Statement: Ethical review and approval were waived for this study, because no medical research was conducted on human subjects. 
Informed Consent Statement: Informed consent was obtained from all subjects involved in the study.

Acknowledgments: The authors would like to thank Maurizio Rossi, who is the director of the master in Lighting Design and LED technology. Special thanks to the three masters' editions students who participated in the workshops on lighting for cultural heritage.

Conflicts of Interest: The authors declare no conflict of interest.

\section{References}

1. Siniscalco, A.; Appollonia, L. Rethinking Lighting and Communication for a Cultural Assets, a Case Study: The Roman Villa La Consolata. SCIRES-IT-SCIentific RESearch Inf. Technol. 2021, 11, 53-62. [CrossRef]

2. Tarasco, A.L. La Redditività del Patrimonio Culturale: Efficienza Aziendale e Promozione Culturale; Giappichelli: Torino, Italy, 2006; ISBN 978-88-348-6629-0.

3. Selmanović, E.; Rizvic, S.; Harvey, C.; Boskovic, D.; Hulusic, V.; Chahin, M.; Sljivo, S. Improving Accessibility to Intangible Cultural Heritage Preservation Using Virtual Reality. J. Comput. Cult. Herit. 2020, 13, 1-19. [CrossRef]

4. Bernardini, F.; Rushmeier, H. The 3D Model Acquisition Pipeline. Comput. Graph. Forum 2002, 21, 149-172. [CrossRef]

5. Atkinson, K.B. (Ed.) Close Range Photogrammetry and Machine Vision; Reprinted; Whittles: Caithness, Scotland, UK, 2009; ISBN 978-1-870325-73-8.

6. Valzano, V.; Negro, F.; Lucarella, D. Otranto Treasures in 3D. SCIRES-IT-SCIentific RESearch Inf. Technol. 2019, 9, 17-28. [CrossRef]

7. Frommel, S.; Apollonio, F.; Gaiani, M.; Bertacchi, G. Some Reconstruction Hypotheses of Leonardo's Project for the Tiburio of the Milan Cathedral by Using 3D Digital Models. SCIRES-IT-SCIentific RESearch Inf. Technol. 2020, 10, 53-66. [CrossRef]

8. Apollonio, F.I.; Gaiani, M.; Sun, Z. BIM-Based Modeling and Data Enrichment of Classical Architectural Buildings. SCIRES-IT 2012, 2, 41-62. [CrossRef]

9. European Heritage Alliance Cultural Heritage: A Powerful Catalyst for the Future of Europe. Available online: https://www. europanostra.org/wp-content/uploads/2020/05/20200509_EUROPE-DAY-MANIFESTO.pdf (accessed on 18 October 2021).

10. Pfarr-Harfst, M. Digital 2D and 3D Visualisations as Iconic Epistemological Models. SCIRES-IT-SCIentific RESearch Inf. Technol. 2020, 10, 19-30. [CrossRef]

11. Bigliardi, G. 3D Virtual Museum. Available online: http:/ / www.3d-virtualmuseum.it/ (accessed on 15 February 2021).

12. Smithsonian Virtual Tour I Smithsonian National Museum of Natural History. Available online: https://naturalhistory.si.edu/ visit/virtual-tour (accessed on 15 April 2021).

13. Palace Museum Virutual Tours I The Palace Museum. Available online: https://en.dpm.org.cn/multimedia/virutual/ (accessed on 15 April 2021).

14. Casa Batlló Casa Batlló-Virtual Tour. Available online: https:/ /www.casabatllo.es/en/virtual-tour/ (accessed on 15 February 2021).

15. Museo Egizio di Torino Museo Egizio. Available online: https://museoegizio.it/en/ (accessed on 9 February 2021).

16. Luovres Online Tours. Available online: https://www.louvre.fr/en/online-tours (accessed on 31 May 2021).

17. Google Google Arts \& Culture. Available online: https:/ /artsandculture.google.com/ (accessed on 9 February 2021).

18. Pascoal, S.; Tallone, L.; Furtado, M. The Impact of COVID-19 on Cultural Tourism: Virtual Exhibitions, Technology and Innovation. Smart Innov. Syst. Technol. 2021, 209, 177-185. [CrossRef]

19. Valzano, V.; Mannino, K. Cultural Heritage Communication and Digital Resources: Three Examples from Messapian Archaeology. SCIRES-IT-SCIentific RESearch Inf. Technol. 2020, 10, 1-18. [CrossRef]

20. Quiñones Vilá, C.S. What's in a Name? Museums in the Post-Digital Age. Santander Art Cult. Law Rev. 2020, 2020, 177-198. [CrossRef]

21. Murano, F. L'illuminazione Delle Opere Nelle Mostre D'arte; Maggioli Editore: Milano, Italy, 2017; ISBN 978-88-916-2600-4.

22. Bonomo, M.; Bertolaja, C.; Paolucci, A. AIDI L'illuminazione Delle Opere D'arte Negli Interni: Guida Alla Progettazione; Ediplan Editrice: Milano, Italy, 2013; ISBN 978-88-96726-09-9.

23. Alvarez-Martin, A.; Trashin, S.; Cuykx, M.; Covaci, A.; De Wael, K.; Janssens, K. Photodegradation Mechanisms and Kinetics of Eosin-Y in Oxic and Anoxic Conditions. Dye Pigments 2017, 145, 376-384. [CrossRef]

24. Iacomussi, P.; Rossi, G. Influence of Visible Radiation on Radiometric Properties of Paints. Surf. Eng. 2008, 24, 90-97. [CrossRef]

25. Bista, D.; Bista, A.; Shrestha, A.; Doulos, L.T.; Bhusal, P.; Zissis, G.; Topalis, F.; Chhetri, B.B. Lighting for Cultural and Heritage Site: An Innovative Approach for Lighting in the Distinct Pagoda-Style Architecture of Nepal. Sustainability 2021, 13, 2720. [CrossRef]

26. Nakajima, Y.; Fuchida, T. Study of museum lighting: Optimum lighting and color environment (3)-New calculation method of color quality index for museum lighting. J. Illum. Eng. Inst. Jpn. 2015, 99, 263-269. [CrossRef]

27. Tuzikas, A.; Žukauskas, A.; Vaicekauksas, R.; Petrulis, A.; Vitta, P.; Shur, M. Artwork Visualization Using a Solid-State Lighting Engine with Controlled Photochemical Safety. Opt. Express 2014, 22, 16802-16818. [CrossRef] [PubMed]

28. Nuzzo, M.; Faella, G. The Carmine Maggiore Bell Tower: An Inclusive and Sustainable Restoration Experience. Sustainability 2021, 13, 1445. [CrossRef]

29. Thickett, D. Managing natural light in historic Properties. In Lights on ... Cultural Heritage and Museums! University of Porto: Porto, Portugal, 2016; p. 264, ISBN 978-989-8648-98-3.

30. Berbaum, K.; Bever, T.; Chung, C.S. Light Source Position in the Perception of Object Shape. Perception 1983, 12, 411-416. [CrossRef] 
31. UNI UNI 11630:2016. Light and Lighting. Criteria for the Preparation of the Lighting Design; Ente Nazionale Italiano di Unificazione: Milano, Italy, 2016.

32. CEN CEN/TS 17165:2018. Light and Lighting-Lighting System Design Process; European Committee for Standardization: Bruxelles, Belgium, 2018.

33. CIE (Ed.) CIE 171:2006. Test Cases to Assess the Accuracy of Lighting Computer Programs; CIE Central Bureau: Vienna, Austria, 2006; ISBN 978-3-901906-47-3.

34. Lighting Analysts Lighting Analysts: Illumination Engineering Software. Available online: https://lightinganalysts.com/ (accessed on 26 May 2021).

35. DIAL GmbH DIALux: The Lighting Design Software for Lighting Designer. Available online: https://www.dialux.com/en-GB/ (accessed on 1 June 2021).

36. Relux Informatik AG Relux. Available online: https:/ / relux.com/en/ (accessed on 1 June 2021).

37. Oxytech OxyTech-Lighting Software, Hardware and Services. Available online: https://www.oxytech.it/en/ (accessed on 1 June 2021).

38. Guarini, G. Nuove Frontiere Della Progettazione BIM Per L'illuminazione, 1st ed.; Politecnica; Maggioli Editore: Milano, Italy, 2020; ISBN 88-916-4632-6.

39. Balocco, C.; Volante, G. A Method for Sustainable Lighting, Preventive Conservation, Energy Design and Technology-Lighting a Historical Church Converted into a University Library. Sustainability 2019, 11, 3145. [CrossRef]

40. Salata, F.; Golasi, I.; Falanga, G.; Allegri, M.; De Lieto Vollaro, E.; Nardecchia, F.; Pagliaro, F.; Gugliermetti, F.; De Lieto Vollaro, A. Maintenance and Energy Optimization of Lighting Systems for the Improvement of Historic Buildings: A Case Study. Sustainability 2015, 7, 10770-10788. [CrossRef]

41. Dang, R.; Liu, R.; Luo, T. Lighting Quantity Indexes for Lighting Paintings in Museums. Build. Environ. 2020, $182,107142$. [CrossRef]

42. Mondal, A.; Ghosh, K. Studies on Germicidal Benefit of Ultra Violet Ray upon Old Paper Documents. Light Eng. 2019, 27, 17-24. [CrossRef]

43. Miccoli, M.; Melis, M. Multi Spectral Light Metering System for Cultural Heritage Diagnosis and Conservation. In Proceedings of the Optics for Arts, Architecture, and Archaeology IV, Munich, Germany, 13-16 May 2013; Volume 8790.

44. Dang, R.; Wang, B.; Song, X.; Zhang, F.; Liu, G. The Mathematical Expression of Damage Law of Museum Lighting on Dyed Artworks. Sci. Rep. 2021, 11, 10951. [CrossRef]

45. Dang, R.; Zhang, F.; Yang, D.; Guo, W.; Liu, G. Spectral Damage Model for Lighting Paper and Silk in Museum. J. Cult. Herit. 2020, 45, 249-253. [CrossRef]

46. Piegari, A.; Polato, P. Wideband Optical Coatings for Artwork Protection from Ultraviolet and Infrared Radiation Damage. In Proceedings of the 19th Congress of the International Commission for Optics: Optics for the Quality of Life, Florence, Italy, 25-30 August 2002; International Society for Optics and Photonics: Bellingham, WA, USA, 2003; Volume 4829, pp. 64-65.

47. Bacci, M.; Cucci, C.; Mencaglia, A.A.; Porcinai, S.; Mignani, A.G. Optical Fibers for Safer Exhibition Conditions in Museums: The Measurement of Equivalent-Light Dose. In Proceedings of the Optical Metrology for Arts and Multimedia, Munich, Germany, 23-26 June 2003; International Society for Optics and Photonics: Bellingham, WA, USA, 2003; Volume 5146, pp. 170-174.

48. CEN CEN/TS 16163:2014. Conservation of Cultural Heritage-Guidelines and Procedures for Choosing Appropriate Lighting for Indoor Exhibitions; European Committee for Standardization: Bruxelles, Belgium, 2014.

49. Nakajima, Y.; Fuchida, T. Study of museum lighting: Optimum lighting and color environment (4) spectral power distribution of light sources in consideration of color appearance of ART under low illuminance. J. Illum. Eng. Inst. Jpn. 2019, 103, 413-420. [CrossRef]

50. Cuttle, C. A Proposal to Reduce the Exposure to Light of Museum Objects without Reducing Illuminance or the Levelofvisual Satisfaction of Museum Visitors. J. Am. Inst. Conserv. 2000, 39, 229-244. [CrossRef]

51. Eng, C.W.; Preusser, F.D.; Schaeffer, T.T. Reflections on Light Monitoring: Evaluating Museum Lighting Options for Modern and Contemporary Art. Stud. Conserv. 2016, 61, 44-48. [CrossRef]

52. Siniscalco, A.; Rossi, M.; Apollonio, F.I. Lighting Design For Monumental Complex: A Case Study. SCIRES-IT-SCIentific RESearch Inf. Technol. 2020, 9, 115-127.

53. Isikoren, S.H.; Aygenc, E. Sustainability of Exhibition Halls While Adapting to Design Concept and Technology in Museums: St. Barnabas Icon and Archaeological Museum Examples. Revista Cercetare Interventie Sociala 2018, 62, 331-351.

54. Leccese, F.; Salvadori, G.; Tambellini, G.; Kazanasmaz, Z.T. Assessing Museums' Daylighting Adequacy without Annual Measurement Campaign: Dataset of a Confrontation between Measured and Simulated Illuminance Values inside the Cetacean Gallery of the Charterhouse of Calci. Data Brief 2020, 32, 106065. [CrossRef]

55. Del Hoyo-Meléndez, J.M.; Mecklenburg, M.F.; Doménech-Carbó, M.T. An Evaluation of Daylight Distribution as an Initial Preventive Conservation Measure at Two Smithsonian Institution Museums, Washington DC, USA. J. Cult. Herit. 2011, $12,54-64$. [CrossRef]

56. Balocco, C.; Cecchi, M.; Volante, G. Natural Lighting for Sustainability of Cultural Heritage Refurbishment. Sustainability 2019, 11, 4842. [CrossRef]

57. Mayorga Pinilla, S.; Vázquez Moliní, D.; Álvarez Fernández-Balbuena, A.; Hernández Raboso, G.; Herráez, J.A.; Azcutia, M.; García Botella, Á. Advanced Daylighting Evaluation Applied to Cultural Heritage Buildings and Museums: Application to the Cloister of Santa Maria El Paular. Renew. Energy 2016, 85, 1362-1370. [CrossRef] 
58. Li, Z.; Gao, W.; Lin, J.; He, X.; Cao, F.; Zou, N. Key Techniques Applied for Lighting Design on Chinese Historical Sites-Taking the Great Wall Resort in Kelan County as an Example. Lect. Notes Inst. Comput. Sci. Soc. Inform. Telecommun. Eng. LNICST 2019, 282, 68-75. [CrossRef]

59. Comune di Milano Photogallery of Albergo Diurno Venezia. Available online: https://www.flickr.com/photos/comune_milano/ sets / 72157642691433983/ (accessed on 6 August 2021).

60. FAI FAI-Fondo Ambiente Italiano. Available online: https://fondoambiente.it/il-fai/mission/ (accessed on 1 August 2021).

61. FAI Abbey of Santa Maria Di Cerrate. Available online: https://www.fondoambiente.it/abbazia-di-santa-maria-di-cerrate-eng/ (accessed on 6 August 2021).

62. Microsoft Skype I Communication Tool for Free Calls and Chat. Available online: https://www.skype.com/en// (accessed on 1 August 2021).

63. Webex by Cisco. Video Conferencing, Cloud Calling \& Screen Sharing. Available online: https://www.webex.com/ (accessed on 2 August 2021).

64. Moodle Moodle. Available online: https://moodle.org/?lang=en (accessed on 10 October 2021).

65. Socrative Socrative. Available online: https://www.socrative.com/ (accessed on 10 October 2021).

66. Web3D Consortium Web3D Consortium I Open Standards for Real-Time 3D Communication. Available online: https: / /www. web3d.org/ (accessed on 19 February 2021).

67. Ubik, S.; Kubišta, J. Interactive Scalable Visualizations of Cultural Heritage for Distance Access. In Proceedings of the Euro-Mediterranean Conference, Nicosia, Cyprus, 31 October-5 November 2016; Springer: Cham, Switzerland, 2016; Volume 10059 LNCS, pp. 191-198, Lecture Notes in Computer Science. [CrossRef]

68. Unity Technologies Unity Real-Time Development Platform /3D, 2D VR \& AR Engine. Available online: https://unity.com/ (accessed on 4 August 2021).

69. Epic Games Unreal Engine I The Most Powerful Real-Time 3D Creation Platform. Available online: https:/ /www.unrealengine. com/en-US/ (accessed on 4 August 2021).

70. Arendash, D. The Unreal Editor as a Web 3D Authoring Environment. In Proceedings of the Ninth International Conference on 3D Web Technology-Web3'04, Monterey, CA, USA, 5-8 April 2004; ACM Press: Monterey, CA, USA, 2004; p. 119. 